\title{
Mental health self-assessment system in the pandemic in Colombia
}

\author{
Augusto Pérez-Gómez*, Alejandra Villamil-Sánchez and \\ Orlando Scoppetta DG
}

Received: 17 December, 2020

Accepted: 31 December, 2020

Published: 01 January, 2021

*Corresponding author: Augusto Pérez-Gómez, Ph.D, Director, New Rumbos Corporation, Associate Professor, University of the Andes, Calle 108 A \# 4-15, Bogota 110111, Colombia, Tel: (571) 619 1152, (57) 310805 9796; Email: aperez@nuevosrumbos.org

Keywords: Coronavirus infections; Mental health; Pandemics; Life style (DeCS)

https://www.peertechz.com

Check for updates

New Rumbos Corporation, Associate Professor, University of the Andes, Calle 108 A \# 4-15, Bogota

110111, Colombia

\begin{abstract}
Background: The COVID-19 pandemic has brought different impacts on human life unfortunately, mental health has not received due attention.

Methods: The Nuevos Rumbos Corporation (CNR) decided to create a self- assessment system that allows measuring the impact that confinement has had in different areas of adjustment in life of Colombians.

Findings: More than 2000 people have used the system, ( $74.2 \%$ women, $24.2 \%$ men and $1.6 \%$ qualify as "other"), about $62 \%$ of the respondents report negative emotional changes, $33 \%$ have felt more aggressive than usual, $12 \%$ reported an increase in alcohol consumption and of active smokers $32.5 \%$ increased their consumption.

Interpretation: As a result of the limitations associated with the pandemic, there is evidence of a global imbalance in the mental health of the population that requires attention, since the problems will increase as the economic problems continue as well as the confinement, associated with a second wave of the virus. Funding: We declare that we have no conflict of interest in the preparation or publication of this paper, Nuevos Rumbos being completely autonomous in the application of the system as well as in the administration of its data.
\end{abstract}

One of the most notable impacts of the COVID-19 pandemic has been the loss of freedom in terms of displacement or encounters with other people. In all the countries of the world there have been more or less prolonged confinements and restrictions on social life for most of the year; but Colombia has been one of the most punished: three months of total confinement, and another three with different types of restrictions, despite which the country is among the most affected by the virus (more than 1'440,000 infected and about 39,000 dead until the second week of December).

Even when the secondary effects of the pandemic are massive (the economy, education, food, entertainment and work), we must take into account that all this has a serious impact on an area of human life that has not been given greater importance in this crisis, but which is fundamental: mental health. In addition, there has also been a strong impact on the health system: not only have huge investments been required in emergency rooms, thousands of surgeries classified as "non-urgent" have been stopped, and health personnel were severely shaken by the sick and the dead caused by the virus among them, but the Primary Health Care Centers (PHCC) had to completely suspend their activities for several months.

The Nuevos Rumbos Corporation (CNR) decided to create a self-assessment system that allows measuring the impact that confinement has had in different areas of adjustment in life of Colombians, as part of its contribution to the search for solutions to the problems created by the pandemic. The system can be easily accessed from the Corporation's website (www. nuevosrumbos.org) and provides individualized feedback.

The self-assessment tool has three sections, and it takes between six and seven minutes to answer. In the first section some sociodemographic data and general conditions of the person's life are asked; the second examines changes in mood, in aggressiveness, in relationships with others, in routines in different fields, in learning, in the consumption of alcohol, 
tobacco and other substances; and the third examines the effects on different areas of life and the vision of the future. When the person finishes filling out the instrument, the feedback is immediate, and they can, if they wish, speak with a CNR professional. The feedback is based on an algorithm that simulates the criteria of a mental health expert to give a more specific feedback to each person. The feedback shows each user if they have signs of emotional distress or anxiety and different areas of their life that could be malfunctioning.

The main results obtained so far are the following: to date, more than 2000 people have used the system, of which $74.2 \%$ are women, $24.2 \%$ are men and $1.6 \%$ qualify as "other"; the average age is 31 years, with a standard deviation of 11.1; the vast majority have higher education ( $55 \%$ university degree and $18.8 \%$ postgraduate); $32.6 \%$ have a partner and $57 \%$ are single; $34 \%$ work full time, $17 \%$ are unemployed and looking for work, $19.7 \%$ are students who do not work and $13.2 \%$ study and work.

When asked if they have experienced negative or positive changes in their mood, about $62 \%$ of the respondents report negative changes and only 15\% positive changes Figure 1.

Regarding whether they have felt more aggressive than usual, 33\% say yes, while about 33\% report ups and downs and $33 \%$ report less aggressiveness; the percentages regarding the question about whether there have been positive or negative changes with the people with whom they live were: $33 \%$ report negative changes, $37 \%$ ups and downs, and $30 \%$ positive changes; and with friends or other people they do not live with, $31 \%, 43 \%$ and $26 \%$, respectively Figure 2 .

About half of all participants report having created work, physical activity, reading, and recreation routines.

An interesting finding concerns alcohol consumption: $12 \%$ reported an increase, $59 \%$ decreased and 30\% kept it the same; the opposite occurs with tobacco: about $16 \%$ smoked before the pandemic, and $32.5 \%$ increased, $19.4 \%$ stayed and $51 \%$ decreased or stopped. And as for illicit substances, $12 \%$ used them before, $22 \%$ increased, $24.4 \%$ remained and $53.8 \%$ decreased or left them Figure 3.

Regarding illegal drugs, almost $22 \%$ showed an increase of their use, around 54\% decreased their consumption and $24 \%$ remained at the same level Figure 4.

$71 \%$ say they do not see the future threatening, while $29 \%$ do see it that way, and this coincides with the perception of whether they see it "hopeful" or not: $74 \%$ see it that way, while $26 \%$ see it hopeless. This contrasts with the answer to the question about whether they see the future positive: $83 \%$ answer negatively, and $17 \%$ think it will be positive.

Regarding the impact on finances, $50 \%$ report a negative impact and $14 \%$ positive; the remaining $35 \%$ report a moderate impact.

One of the most significant effects is emotional distress: $72 \%$ would have signs of emotional distress, $63 \%$ would have anxiety, and $80 \%$ would have either of the two.

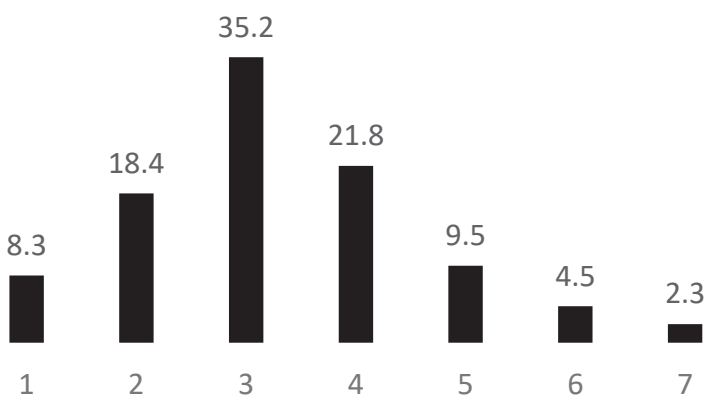

Figure 1: Changes in mood: 1 more negative, 7 more positive (\%).

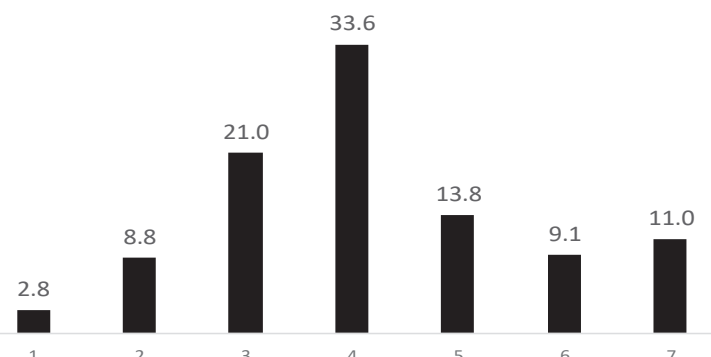

Figure 2: Changes in aggressiveness: 1 more aggressive, 7 less aggressive (\%).

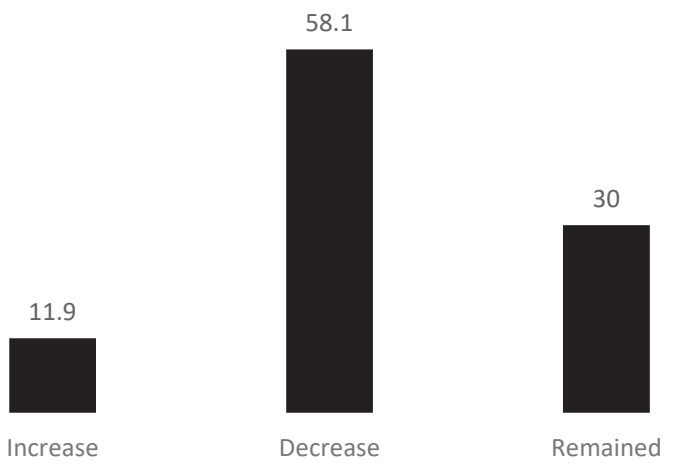

Figure 3: Changes in alcohol consumption.

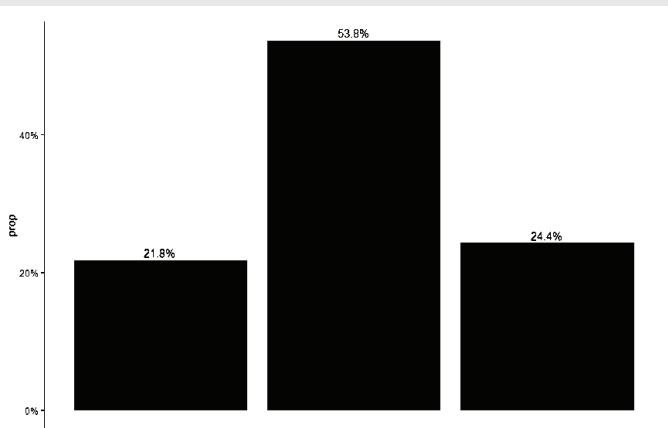

Figure 4: Changes in illegal drugs use.

\section{Conclusions}

As a result of the limitations associated with the pandemic, the majority of the Colombian people who answered to the self-evaluation system show negative changes in their mood $(62 \%)$, an increase in aggressiveness $(33 \%)$ and symptoms of emotional distress and anxiety (more than $70 \%$ ). 
The complex consequences of the pandemic on mental health are related to negative changes in matters of great importance such as the economy. $50 \%$ of the population has seen their finances negatively affected, while only $14 \%$ have seen them improve; It is likely that this percentage of negative impact is higher in economically less favored populations than those that used this instrument.

Even if the vision of the future is not excessively negative, it is not positive either. Probably the best word to express what seems to emerge from these perceptions is "uncertainty": a strongly ambivalent uncertainty, but not necessarily pessimistic.

Alcohol consumption has been reduced and could be considered a positive effect of the pandemic. But several elements must be taken into account to better understand this data:

a. The average Colombian does not drink alcohol alone, but does so at parties, meetings, bars, restaurants, and nightclubs: all these spaces have been closed during these months; restaurants were only reopened in August 2020, and still with serious restrictions regarding alcohol.

b. During several months the sale of alcoholic beverages was strongly controlled throughout the country; in some places a dry law was imposed for many days and weekends.

c. Confinement imposed obvious forms of control over excesses and even consumption in small quantities. Something very similar can be said with regard to illicit substances.
This temporary decrease in alcohol consumption will possibly be reversed as soon as the confinement is suspended, and all the usual places of consumption are opened. The authorities would take note of this possibility and initiate work in a timely manner that prevents the increase in accidents and acts of violence when this occurs.

The main conclusions of this analysis show a global imbalance in the mental health of the population that requires attention, since the problems will increase as the economic problems and the confinement continue, associated to a second wave of the virus. It should not be forgotten that those who have responded to the instrument so far represent to a large extent a relatively economically and educationally privileged sector of the population, which makes it possible to foresee greater resources to face these difficulties; so that the effects on more fragile socioeconomic levels can be much greater.

\section{Ethical considerations}

All the ethical principles for the investigation established by Resolution 8430 of 1993 and Law 1090 of 2006 were taken into account, guaranteeing voluntary participation, anonymity and confidentiality; and obtaining the passive consent of all participants.

\section{Declaration of interests and contributors statement}

All authors participated in the review of the underlying data, writing and analysis of the article.

We declare that we have no conflict of interest in its preparation or publication, Nuevos Rumbos is completely autonomous in the application of the system as well as in the administration of its data.

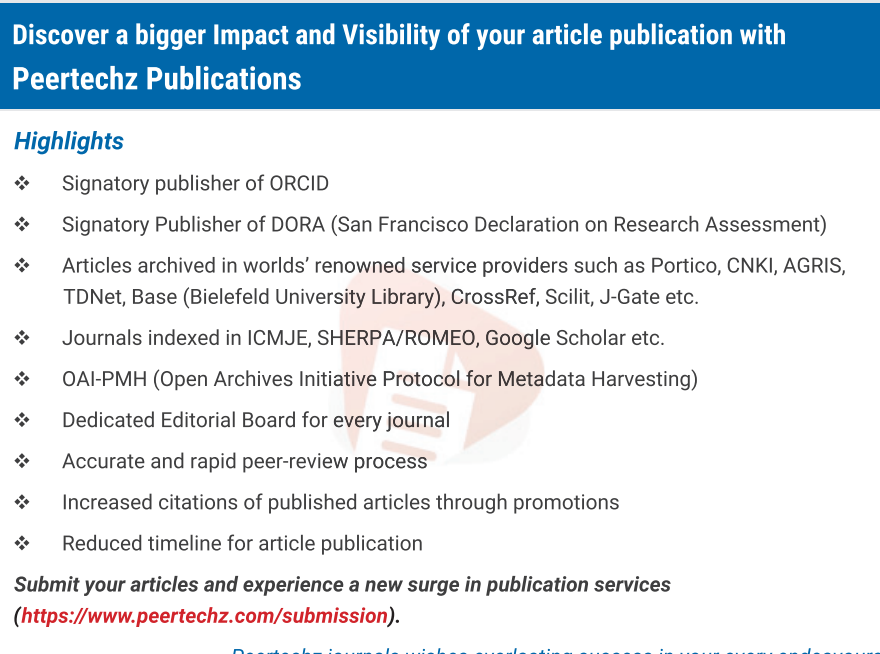

Copyright: @ 2021 Pérez-Gómez A, et al. This is an open-access article distributed under the terms of the Creative Commons Attribution License, which permits unrestricted use, distribution, and reproduction in any medium, provided the original author and source are credited.

Citation: Pérez-Gómez A, Villamil-Sánchez A, Orlando Scoppetta DG (2021) Mental health self-assessment system in the pandemic in Colombia. J Addict Med Ther Sci 7(1): 001-003. DOI: https://dx.doi.org/10.17352/2455-3484.000046 